\title{
Graphene Oxide Nanosheets as Effective Friction Modifier for Oil Lubricant: Materials, Methods, and Tribological Results
}

\author{
Adolfo Senatore, ${ }^{1,2}$ Vincenzo D'Agostino, ${ }^{1,2}$ Vincenzo Petrone, $^{2}$ \\ Paolo Ciambelli, ${ }^{1,2}$ and Maria Sarno ${ }^{1,2}$ \\ ${ }^{1}$ Department of Industrial Engineering, University of Salerno, 84084 Fisciano, Salerno, Italy \\ ${ }^{2}$ NANO_MATES Research Centre, University of Salerno, 84084 Fisciano, Salerno, Italy \\ Correspondence should be addressed to Adolfo Senatore; a.senatore@unisa.it
}

Received 31 December 2012; Accepted 20 January 2013

Academic Editors: J. Antunes, J. H. Jang, Y. Lu, J. Mao, and P. Sahoo

Copyright (C) 2013 Adolfo Senatore et al. This is an open access article distributed under the Creative Commons Attribution License, which permits unrestricted use, distribution, and reproduction in any medium, provided the original work is properly cited.

\begin{abstract}
The tribological behaviour of graphene oxide nanosheets in mineral oil was investigated under a wide spectrum of conditions, from boundary and mixed lubrication to elastohydrodynamic regimes. A ball-on-disc setup tribometer has been used to verify the friction reduction due to nanosheets prepared by a modified Hummers method and dispersed in mineral oil. Their good friction and antiwear properties may possibly be attributed to their small structure and extremely thin laminated structure, which offer lower shear stress and prevent interaction between metal interfaces. Furthermore, the results clearly prove that graphene platelets in oil easily form protective film to prevent the direct contact between steel surfaces and, thereby, improve the frictional behaviour of the base oil. This evidence is also related to the frictional coefficient trend in boundary regime.
\end{abstract}

\section{Introduction}

In the field of tribological applications, nanoparticles as additives in base oil have been extensively investigated. These studies refer to synthesis and preparation of nanoscale particles and their tribological properties and friction reduction mechanisms. It has been found that when the nanoparticles were added to base oil, the extreme pressure property and load-carrying capacity were improved and friction coefficient was decreased.

In the past few years, nested spherical supramolecules of metal dichalcogenide have been synthesized by the reaction of metal oxide nanoparticles with $\mathrm{H}_{2} \mathrm{~S}$ at elevated temperatures. Because of their nested fullerene-like structure, these species are known as inorganic fullerene-like (IF) nanoparticles. The IF nanoparticles exhibited improved tribological behaviour compared to the microscale platelets for their robustness and flexibility. The tribological properties of fullerene-like nanoparticles as additives to liquid lubricants were studied in [1-4].

Recently, due to high load-bearing capacity, low surface energy, high chemical stability, weak intermolecular, and strong intramolecular bonding, nanocarbon materials have received a great attention by tribology researchers. In recent years, graphene platelets due to their unique structure and remarkable properties have been the focus of interest in studies on practical applications. However, few studies on the tribological applications of graphene platelets have been reported so far. A number of researchers have reported that graphite [5] and some graphite derivatives $[6,7]$ as well as other lubricant materials [8-10] together have the above desirable properties. Lin et al. [11] investigated the tribological properties of graphite nanosheets as an oil additive. These materials are characterized by weak interatomic interactions between their layers (Van der Waals forces), low strength shearing [12]. In [13], the tribological behaviours of graphene sheets modified by oleic acid and dispersed in lubricant oil were investigated using a four-ball tribometer.

Huang et al. [14] investigated the tribological properties of graphite nanosheets as an oil additive. They found that the frictional behaviour and antiwear ability of the lubricating oil were improved when graphite nanosheets were added to the paraffin oil at the optimal concentration. 
In particular, to ensure uniform dispersion without any agglomeration of the graphene oxide (GO) in the base oil, taking advantage of the surface $-\mathrm{OH}$ and $-\mathrm{COOH}$ introduced during the GO preparation, a functionalization with long chain compounds (i.e., aliphatic amine to obtain the amide derivative) enhances the dispersion in nonpolar solvents [11].

On the other hand, the additives such as carbon and even more if functionalized with $-\mathrm{OH}$ and $-\mathrm{COOH}$ groups that increase their polarity, can be dispersed through the use of a dispersant [13], avoiding further chemical reactions and using a methodology well known to the lubricant industry.

We chose, at the best of our knowledge for the first time, to add graphene oxide using a dispersant.

In the present study, the tribological behaviour of graphene nanosheets in group I base mineral SN150 was investigated under a very wide spectrum of conditions, that is, from boundary and mixed lubrication to the elastohydrodynamic (EHL) regimes. To explore the performances of the nanosheets in the lubricating fluid, a rotational tribometer with a ball-on-disc setup has been employed.

Raman analysis on the steel ball worn surfaces was performed to investigate the presence of graphitic material on the mating surfaces after tribological tests, in order to verify the formation of a protective film on the rubbing surfaces due to the additive.

\section{Experimental}

\subsection{Nanosheets Preparation and Characterization}

2.1.1. Materials. Graphene oxide (GO) nanosheets were prepared at the laboratories of the NANO_MATES centre by a modified Hummers and offeman method [15]. The oxidation of graphite particles were obtained from Lonza $[16,17]$ to graphitic oxide accomplished with a water-free mixture of concentrated sulfuric acid, sodium nitrate, and potassium permanganate. The entire process requires less than two hours for completion at temperatures below $45^{\circ} \mathrm{C}$. With the aid of a further sonication step, the oxidized graphite layers were exfoliated from each other. Then $30 \% \mathrm{H}_{2} \mathrm{O}_{2}$ was added to the suspension to eliminate the excess $\mathrm{MnO}_{4}^{-}$. The desired products were rinsed with deionized water. The remaining salt impurities were eliminated with resinous anion and cation exchangers. The dry form of graphitic oxide was obtained by centrifugation followed by dehydration at $40^{\circ} \mathrm{C}$.

A polyisobutenyl succinic acid-polyamine ester was sonicated with the GO nanosheet in base oil To provide dispersion stability of the additive; the weight ratio GO/dispersant was 3.5. The dispersant has a polar head that attaches itself to the solid particles and a very long hydrocarbon tail that keeps it suspended in oil.

Once several dispersant polar heads have attached themselves to a solid particle, the dispersant can no longer combine with other particles to form large aggregates, enwrapping one nanoparticle to repel another and thereby form a uniform suspension.

2.1.2. Characterization Methods. Scanning electron microscopy (SEM) pictures were obtained with an LEO 1525 microscope. The samples, without any pretreatment, were covered with a $250 \AA$ thick gold film using a sputter coater (Agar 108 A). Raman spectra were obtained at room temperature with a micro-Raman spectrometer Renishaw inVia with $514 \mathrm{~nm}$ excitation wavelength (laser power $30 \mathrm{~mW}$ ) in the range $100-3000 \mathrm{~cm}^{-1}$. Optical images were collected with the optical microscopy connected on line with the Raman instruments. XRD measurements were performed with a Bruker D8 X-ray diffractometer using CuK $\alpha$ radiation. Micro X-ray diffraction patterns were obtained by a $\mu \mathrm{X}$-ray diffractometer (Rint Rapid, Rigaku Corporation).

2.2. Tribological Tests Description. In this study, the investigated tribopair was composed by an upper rotating disc and a lower ball specimen completely flooded in a temperaturecontrolled lubricant bath in line with the features of the used tribometer, Wazau TRM100. The upper element of the tribopair was an X155CrVMo12-1 steel disc, 60 HRC, roughness $R_{a}=0.50 \mu \mathrm{m}$, and $105 \mathrm{~mm}$ diameter, and the lower one was an X45Cr13 steel ball, 52-54 HRC, and $8 \mathrm{~mm}$ diameter.

The normal force to the ball/disc contact was delivered by a lever system and could be varied in the range of 0 $100 \mathrm{~N}$; its value was measured through a load cell placed under the specimen holder. The following average Hertzian pressures were used at the ball/disc interface with normal load given in brackets: $1.17 \mathrm{GPa}(30 \mathrm{~N}), 1.47 \mathrm{GPa}(60 \mathrm{~N})$, and $1.68 \mathrm{GPa}(90 \mathrm{~N})$. The tests were performed for three different temperatures, 25,50 , and $80^{\circ} \mathrm{C}$, and the lubricant average temperature has been kept constant through a $\mathrm{NiCr}-$ $\mathrm{Ni}$ thermocouple in the oil reservoir and an electric resistance driven by a digital controller. This control system allows a control range from room temperature up to $100^{\circ} \mathrm{C}$.

Speed-sweep tests at constant load on broad sliding speed range have been performed to cover different lubrication regimes with the aim of minimizing the modification of the tribopair steel surfaces. For this reason, the time extension of each test was limited to 16 minutes. The disc speed rose up to $2.20 \mathrm{~m} / \mathrm{s}$ in the first 4 minutes and dropped to zero in the following 4 minutes. This speed pattern was repeated twice. The current design of this experiment allowed obtaining a complete Stribeck frictional graph.

The tests were performed for three different temperatures, that is, 25,50 , and $80^{\circ} \mathrm{C}$. All the samples have been stirred before each test for 20 minutes by means of a Turrax T25 Digital Homogenizer with adjustable speed. No chemical dispersant agents were used in order to explore the benefits coming from the pure addition of nanoparticles.

Tests were also carried out to analyse the influence of GO addition to the base oil on wear behaviour of the steel ball/disc tribopair through steady state rubbing tests, see Section 3.2.2. For these tests, constant values for average hertzian pressure, temperature and speed were chosen.

\section{Results and Discussion}

3.1. Graphite and GO Characterization. Graphite chips and GO nanosheets are shown in Figures 1(a), 1(b), 1(c), and 1(d), respectively. The images at higher magnification (Figures 1(b) 


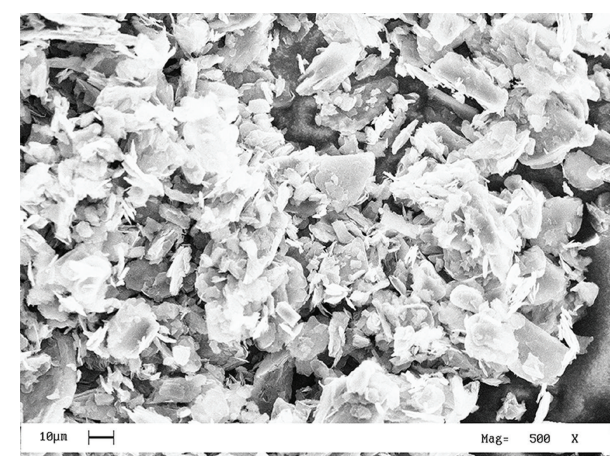

(a)

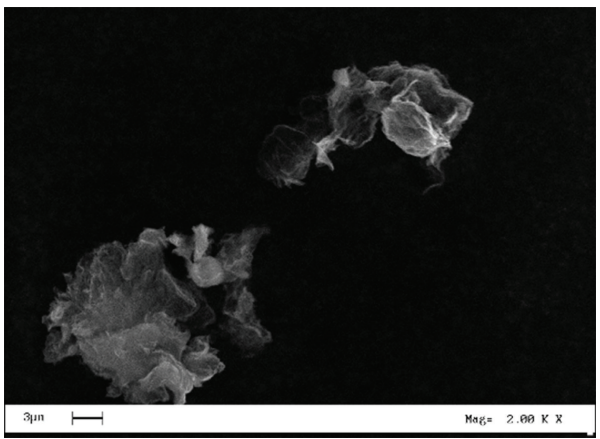

(c)

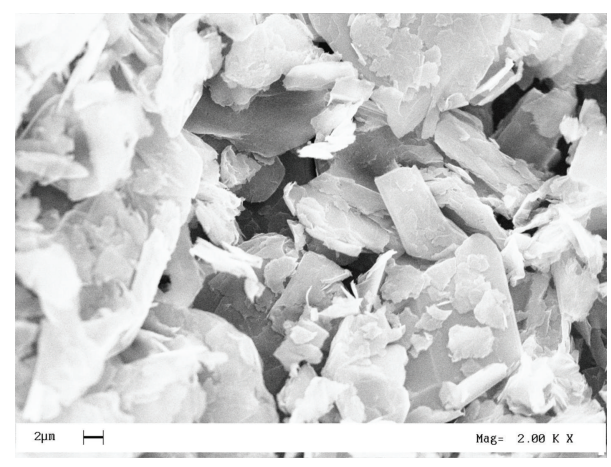

(b)

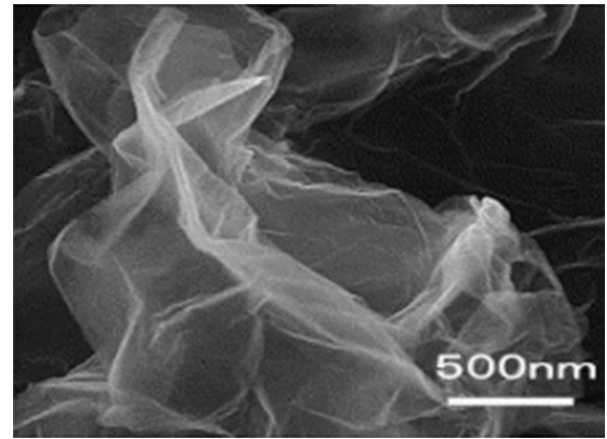

(d)

Figure 1: Graphite (a, b), GO (c, d).

and $1(\mathrm{~d})$ ) evidence the loss of the chips structure of original graphite to GO transparent and thin flakes.

\subsection{Tribological Characterization}

3.2.1. Friction Coefficient. The measured data are presented according to the Stribeck curves representation, that is, friction coefficient versus sliding speed. Below are shown the results obtained for the lubricant sample formulated with GO nanosheets for different levels of temperature and average hertzian contact pressure. The main properties of the base oil were kinematic viscosity, $29.7 \mathrm{cSt}$ at $40^{\circ} \mathrm{C}, 5.1 \mathrm{cSt}$ at $100^{\circ} \mathrm{C}$; density at $20^{\circ} \mathrm{C}, 0.87 \mathrm{~kg} / \mathrm{m}^{3}$.

The set of graphs below (Figure 2) introduces the Stribeck curves exhibited in the sliding tests by the SN 150 oil with $0.1 \mathrm{wt} \%$ GO nanosheets at different levels of average hertzian contact pressure and lubricant temperature, along with the error bars denoting the standard deviation around the rolling mean.

Those results show the decrease of the friction coefficient for increasing average hertzian contact pressure for the formulated sample; the same behaviour has been observed for the base oil according to a point-contact studied effect: the shear stress increases less in proportion to the contact pressure; this leads to a slight reduction of friction [18]. As expected, for a given sample, the minimum of the Stribeck curve moves right for increasing temperature due to the lower viscosity. Additionally, for each sample, the CoF increased with the temperature at a given level of speed and contact pressure. This observation could mainly be addressed to the effect of the lower lubricant viscosity and the ensuing GO precipitation at higher temperature.

A comparison between the samples SN150 with $0.1 \mathrm{wt} \%$ GO and the SN150 base oil shows that reduction of the friction coefficient for the sample with graphene nanoparticles is remarkable (Figures 3(a) and 3(f)).

The Stribeck graphs in Figure 3 for average hertzian pressure equal to $1.17 \mathrm{GPa}, 1.47 \mathrm{GPa}$, and $1.68 \mathrm{GPa}$ show a shape with a well-developed minimum that is considered the transition from mixed lubrication regime to EHL regime for increasing speed [19]. This frontier divides the region with concurrent phenomena of solid-to-solid contacts, adhesion, and interaction between friction modifier additives and steel surface (mixed lubrication) from the other with predominant viscous stress and elastic deformation of the tribopair surfaces (EHL). For instance, the transition appears in the speed range $0.30-0.40 \mathrm{~m} / \mathrm{s}$ for the test at $25^{\circ} \mathrm{C}$ and $0.50-0.60 \mathrm{~m} / \mathrm{s}$ at a higher temperature of $80^{\circ} \mathrm{C}$.

These tests confirm that using graphene nanoparticles in lubricants enhances the friction reduction in boundary, mixed, and EHL lubrication regimes.

For instance, with average contact pressure of $1.17 \mathrm{GPa}$ and temperature in the range $25-80^{\circ} \mathrm{C}$, the average friction coefficient decreased by $20 \%$ of the base lubricant value, but a similar average reduction could be observed for all the combinations of the operating conditions. Even in the heaviest 


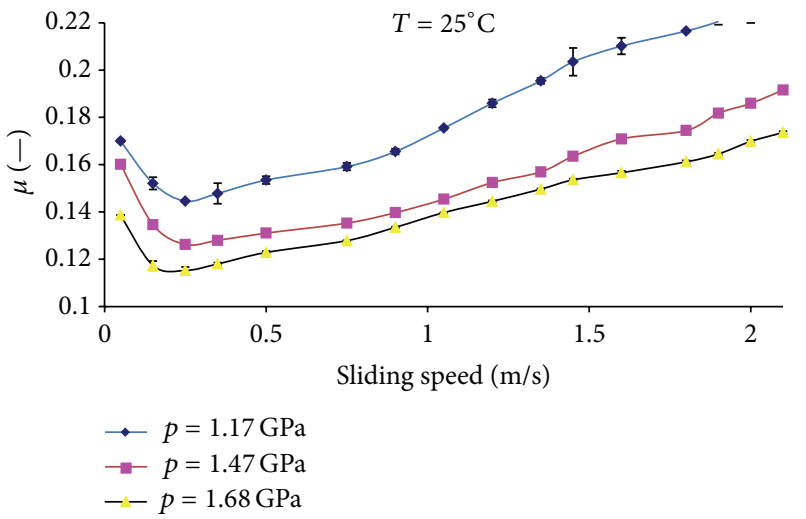

(a)

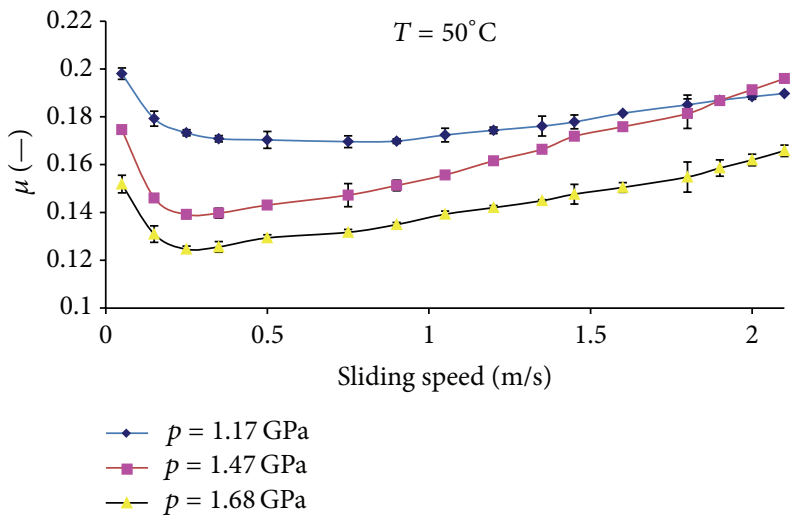

(b)

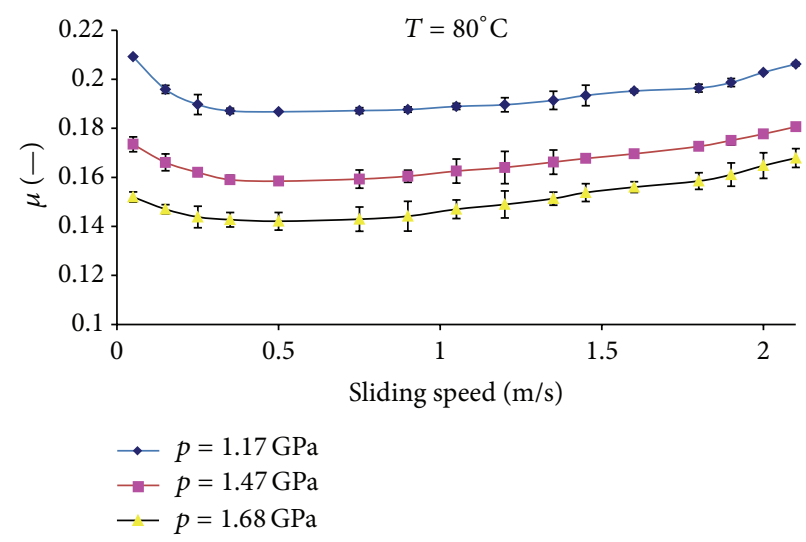

(c)

FIGURE 2: Stribeck curves comparison from the sweep speed test for three different average Hertzian contact pressures 1.17, 1.47, and 1.68 GPa at (a) $25^{\circ} \mathrm{C}$, (b) $50^{\circ} \mathrm{C}$, and (c) $80^{\circ} \mathrm{C}$. Sample: SN 150 oil with $0.1 \mathrm{wt} \%$ GO nanosheets.

TABLE 1: Friction coefficient in steady boundary and EHL lubrication conditions at $25^{\circ} \mathrm{C}$.

\begin{tabular}{|c|c|c|c|}
\hline \multirow{3}{*}{ Sample } & Average Hertzian contact pressu & e $1.68 \mathrm{GPa}$, oil temperature $25^{\circ} \mathrm{C}$ & \multirow[b]{2}{*}{ Difference } \\
\hline & $\begin{array}{l}\text { Average friction coefficient at } 5.0 \mathrm{~mm} / \mathrm{s} \text { sliding } \\
\text { speed }\end{array}$ & $\begin{array}{l}\text { Average friction coefficient at } 0.50 \mathrm{~m} / \mathrm{s} \text { sliding } \\
\text { speed }\end{array}$ & \\
\hline & Boundary regime & EHL regime & \\
\hline SN150_base oil & 0.158 & 0.142 & Benchmark \\
\hline SN150 with $0.1 \mathrm{wt} \% \mathrm{GO}$ & 0.136 & 0.118 & $-14 \%$ \\
\hline
\end{tabular}

test conditions (high pressure and temperature) and in fully developed EHL regime where the viscous stress are prevalent, the CoF reduction is greater than $8 \%$ (Figure 3(f)).

One-hour sliding tests were also performed to analyse the influence of the progressive wearing of the mating materials on the friction coefficient (Figure 4). The average friction coefficients measured during these steady state tests are presented in Tables 1 and 2. According to ISO/IEC Guide 98-3:2008, the average friction coefficients are presented with expanded uncertainty equal to $5 \times 10^{-3}$, coverage factor $k=2$.

The lubrication regimes in these tables and Figure 4 are identified according to the results of the Stribeck curves.
3.2.2. Wear Parameter. At the end of each 1-hour steady state test, the worn surface of the steel ball has been measured with an optical microscope to acquire the wear scar diameter (WSD). The WSD values are reported in Tables 3 and 4. According to ISO/IEC Guide 98-3:2008, the wear scar diameter (WSD) results are listed with expanded uncertainty equal to $20 \mu \mathrm{m}$, coverage factor $k=2$.

The antiwear property of GO as additive for liquid lubricants has been clearly exhibited in all the lubrication regimes.

In particular, the presence of graphene oxide allowed reductions of the ball wearscar diameter equal to $12 \%, 27 \%$, and $30 \%$ in boundary, mixed, and EHL regime, respectively. 


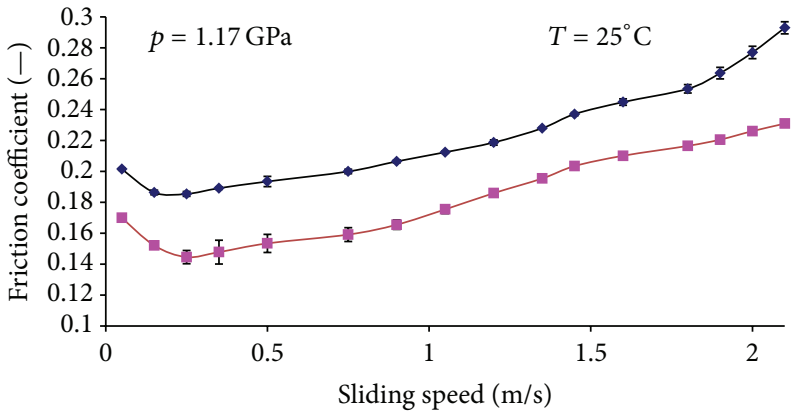

(a)

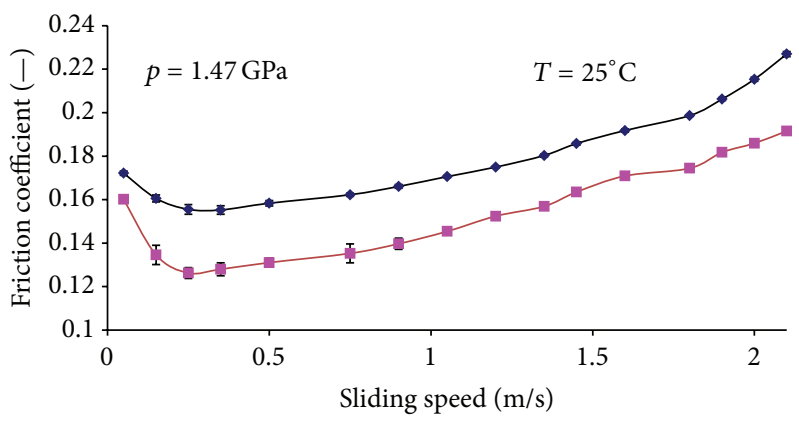

(c)

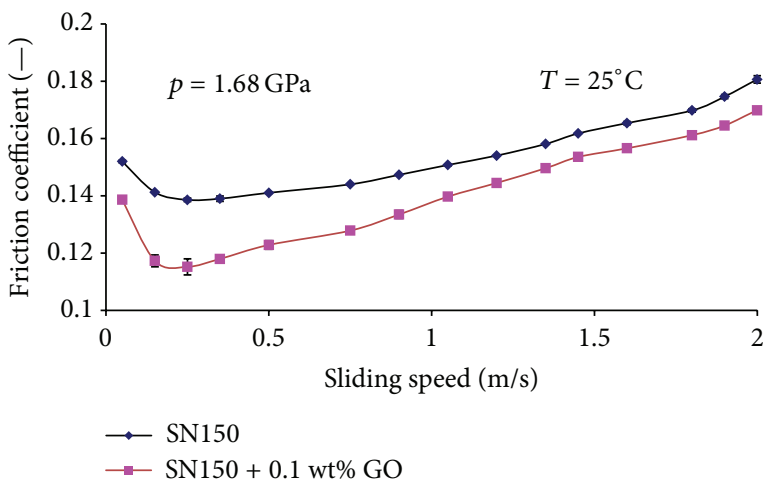

(e)

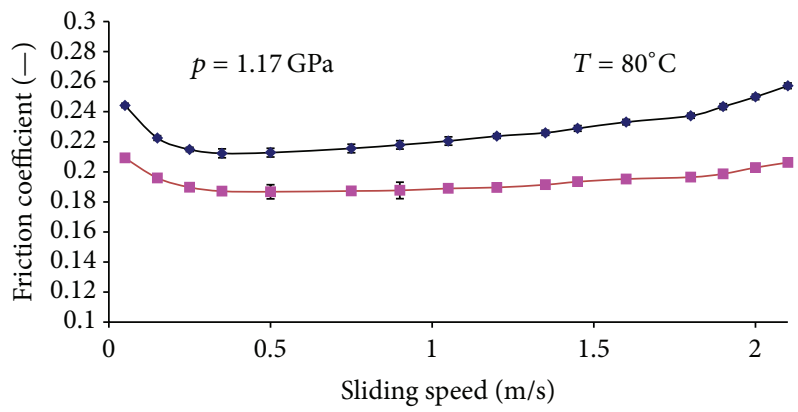

(b)

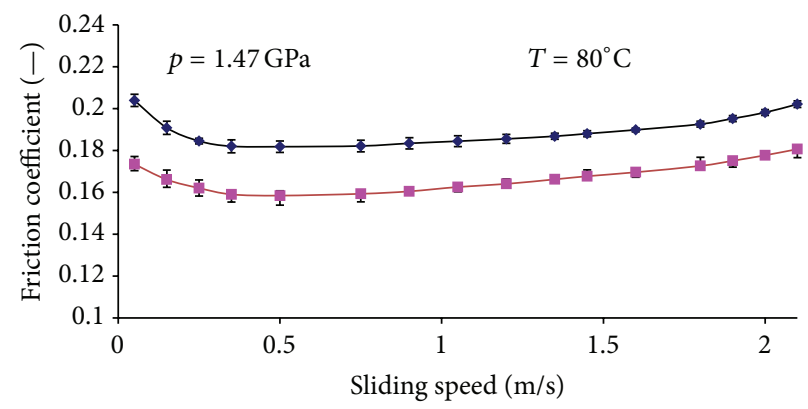

(d)

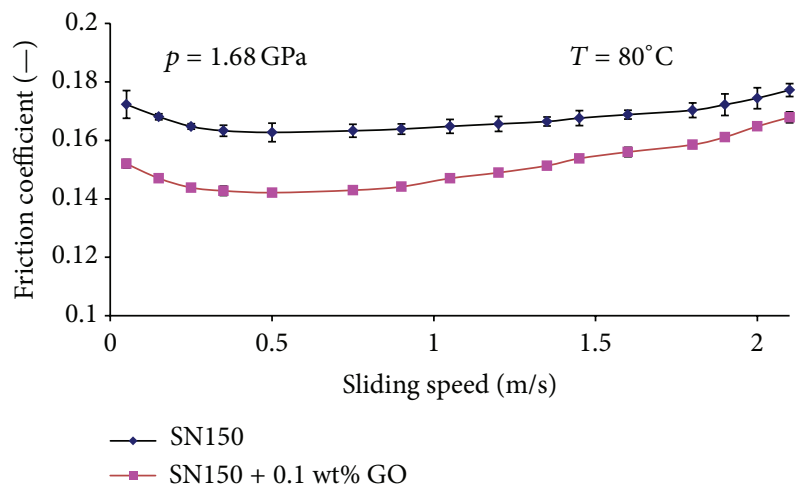

(f)

FIGURE 3: Stribeck curves comparison from the sweep-speed test (SN150—black, SN150 with 0.1 wt\% GO-red).

TABLE 2: Friction coefficient in steady boundary and mixed lubrication conditions at $80^{\circ} \mathrm{C}$.

Average Hertzian contact pressure $1.68 \mathrm{GPa}$, oil temperature $80^{\circ} \mathrm{C}$

Sample

Average friction coefficient at $5.0 \mathrm{~mm} / \mathrm{s}$ sliding Average friction coefficient at $0.50 \mathrm{~m} / \mathrm{s}$ sliding speed speed

Difference

Boundary regime

Mixed regime

\begin{tabular}{lllc}
\hline SN150-base oil & 0.173 & 0.163 & Benchmark \\
SN150 with 0.1 wt\% GO & 0.141 & 0.139 & $-18 \%$ \\
\hline
\end{tabular}

3.3. Raman Spectrum of the Worn Surface. In Figure 5 the Raman spectra of graphite and graphene oxide nanosheets are reported. In particular, in the spectrum of graphite, the most prominent features [20], the so-called G band appearing at $1582 \mathrm{~cm}^{-1}$ [21] and the $\mathrm{G}^{\prime}$ or $2 \mathrm{D}$ band at about $2700 \mathrm{~cm}^{-1}$, using $514 \mathrm{~nm}$ excitation wavelength, are collected. The $\mathrm{G}^{\prime}$ band at room temperature can be fitted with two Lorentzian lines. A broad D band due to disorder or edge [22] of a graphite sample can be also seen at about half of the frequency of the $\mathrm{G}^{\prime}$ band (around $1350 \mathrm{~cm}^{-1}$ using $514 \mathrm{~nm}$ laser excitation). The oxide graphene shows, as expected, an improved D band intensity and flattening of the 2D line and displays a shift to higher frequencies (blue shift) of a broader $\mathrm{G}$ band [23]. In Figure 5, the Raman spectrum collected on 


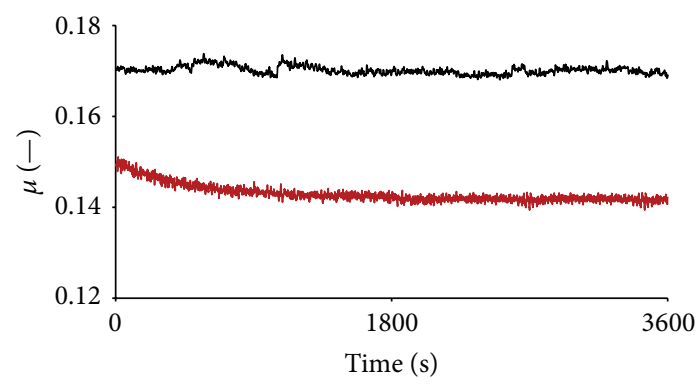

(a)

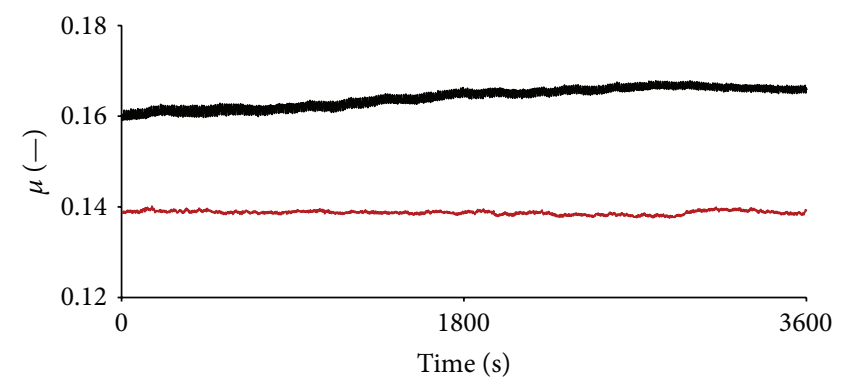

(b)

FIGURE 4: Friction coefficient in a 1-hour steady state test with average hertzian contact pressure $1.68 \mathrm{GPa}$ and oil temperature $80^{\circ} \mathrm{C}$. (a) Sliding speed $5.0 \mathrm{~mm} / \mathrm{s}$, boundary regime; (b) sliding speed $0.50 \mathrm{~m} / \mathrm{s}$, mixed regime (SN150— black, SN150 with $0.1 \mathrm{wt} \% \mathrm{GO}$ - red).

TABLE 3: Wear scar diameter (WSD) after a 1-hour boundary and EHL regime test at $25^{\circ} \mathrm{C}$.

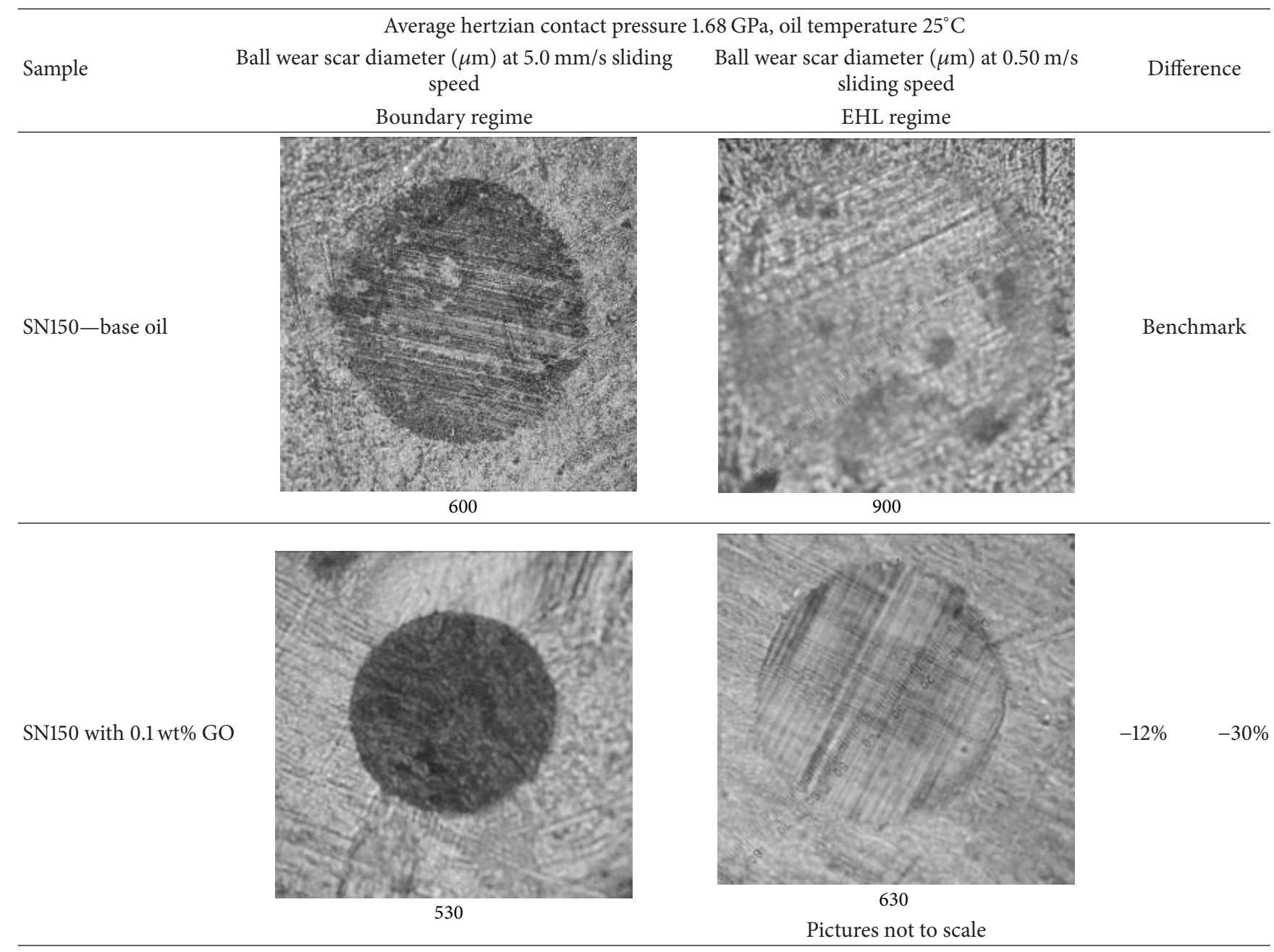

the ball wear after a 2-hour test at $p=1.68 \mathrm{GPa}, T=25^{\circ} \mathrm{C}$, and $v=0.5 \mathrm{~m} / \mathrm{s}$ is also reported. A notable fact is that the $\mathrm{G}$ band of this spectrum is located almost at the same frequency as that in graphite, while the $G^{\prime}$ band exhibits a single Lorentzian feature and the D band results are reduced, evidencing the presence of a thin carbon film ("tribofilm") on the wear scar surface.
3.4. Discussion. The incessant literature dispute on the friction reduction mechanism introduced by nanoparticles as lubricant additives finds in the following list the more convincing physical explanations: rolling-sliding "rigid" motions together with flexibility properties [24-26], nanoadditive exfoliation and material transfer to metal surface to form the so-called "tribofilm" or "tribolayer" [1-3], electronic effects 
TABLE 4: Wear scar diameter (WSD) after a 1-hour boundary and a mixed regime test at $80^{\circ} \mathrm{C}$.

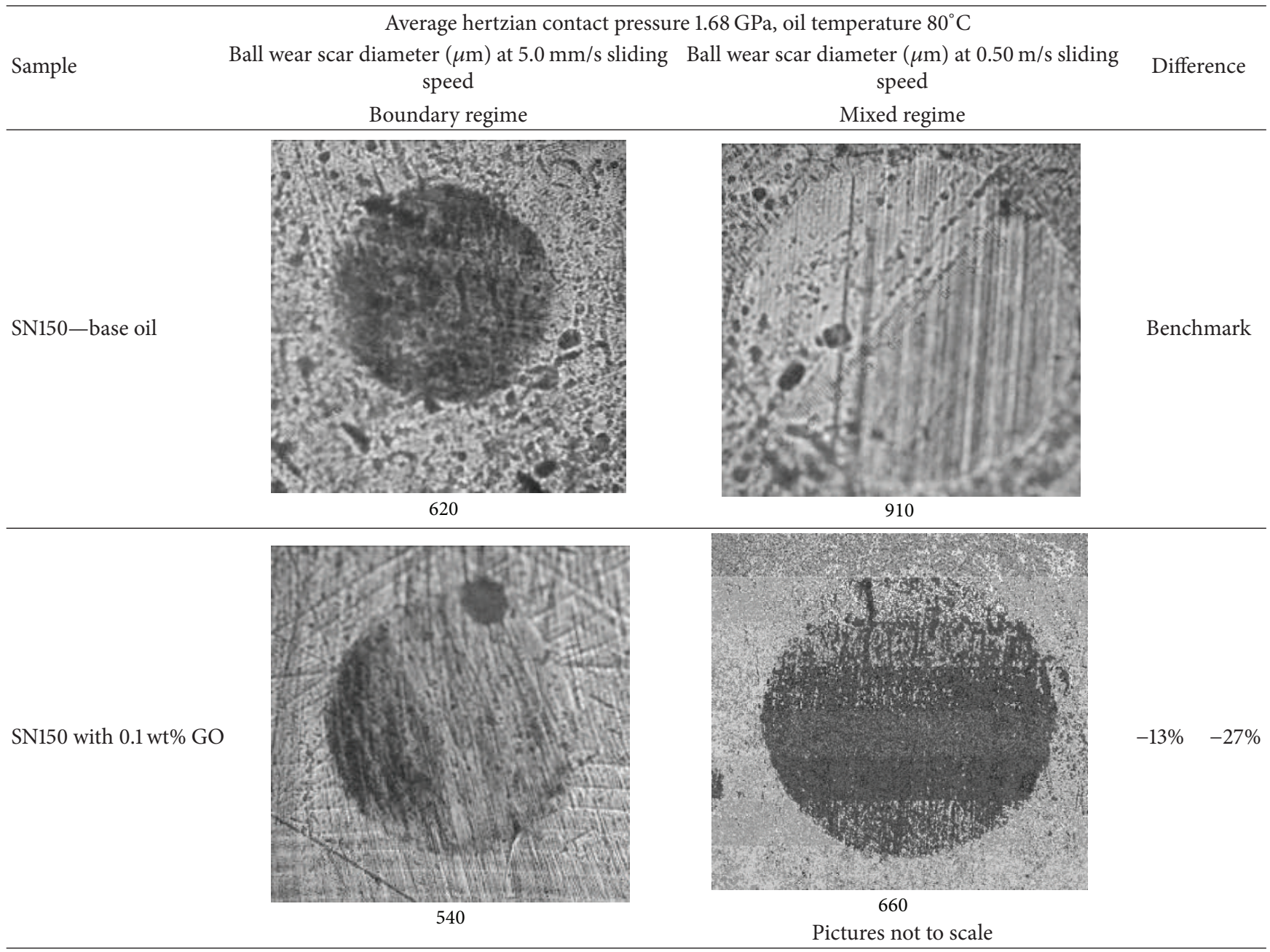

in tribological interfaces [3, 27, 28], and surface roughness improvement effect or "mending" [29]; along with the more classical hypothesis of surface sliding on lower shear stress layers due to weak interatomic forces, valid also for microscale additives used from decades.

The experimental evidences of this paper could represent a proof of the presence of a tribological film of reduced graphene oxide which covers the whole worn surface of the steel ball. The since-start reduction of friction coefficient in Figure 4 could be addressed to the surface rubbing through the low shear stress GO layers. The smoothly decreasing friction coefficient in boundary regime in Figure 4(a) may be related to the tribofilm development.

The GO $0.1 \mathrm{wt} \%$ concentration is quite lower than the usual one for inorganic nanoadditives [1, 3] and carbon nanotubes [30] and in line with previous studies in which oleic acid-modified graphene was used [13]. This feature is welcomed in the preparation of fully formulated engine or gearbox lubricants since the GO addition could only slightly modify the delicate equilibrium achieved by oil

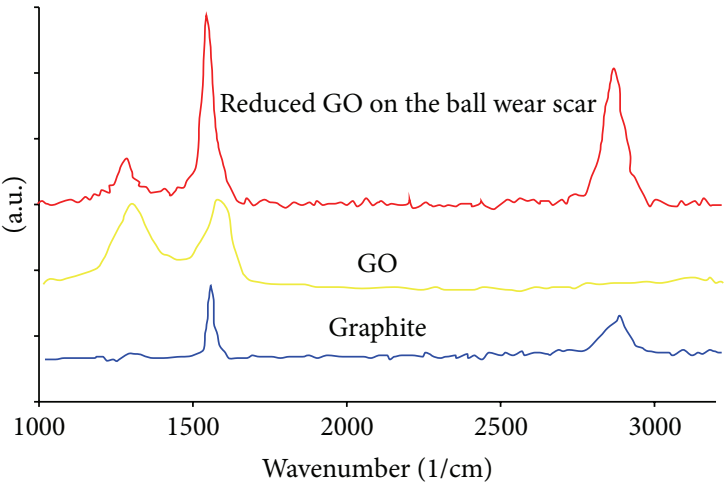

FIGURE 5: Raman spectra of graphite, GO, and reduced GO on the ball wear scar after a 2-hour sliding test.

manufacturers between the essential and ubiquitous additives as antioxidant, viscosity modifier, pour point depressant, and other minors. 


\section{Conclusions}

The tribological tests confirm good reduction of friction and wear parameters in boundary lubrication, mixed lubrication and EHL regimes achieved with mineral oils formulated with graphene oxide (GO) nanosheets prepared at the laboratories of the NANO_MATES research centre. For instance, with average contact pressure of $1.17 \mathrm{GPa}$ and temperature in the range $25-80^{\circ} \mathrm{C}$, the average $\mathrm{CoF}$ decreased by more than $20 \%$ compared with the base lubricant value. The sliding tests in steady state conditions have shown an average reduction of CoF equal to $16 \%$. The frictional reduction benefit has been proven at any level of oil temperature, contact pressure, and sliding speed.

The best antiwear result has been observed on the ball surface in the mixed lubrication and EHL regime, with a marked average decreasing around 30\%. A tribological film of reduced GO nanosheets after the tribological test covers the ball wear scar.

The tendency to the precipitation is a drawback for the formulated sample at the higher temperatures due to the lower lubricant viscosity.

The good friction and antiwear properties of graphene sheets may possibly be attributed to their small structure and extremely thin laminated structure, which offer lower shear stress and prevent interaction between metal interfaces.

The results clearly prove that graphene platelets in oil easily form protective deposited films to prevent the rubbing surfaces from coming into direct contact and, thereby, improve the entirely tribological behaviour of the oil.

Future works will be addressed toward: methods for dispersion improvement of GO in oil, addition to other bases and fully formulated oils, search of optimal concentration, and testing at lower contact pressure to verify the existence of activation threshold related to nanoparticles structure modification.

\section{Acknowledgment}

This research was partially supported by the project "Tribological study of nanoadditives for lubricants and interactions at the interface with the mechanical coupling/Studio tribologico di nanoadditivi per lubrificanti ed interazioni all'interfaccia con le superfici dell'accoppiamento meccanico" funded by the University of Salerno, Italy.

\section{References}

[1] R. Greenberg, G. Halperin, I. Etsion, and R. Tenne, "The effect of $\mathrm{WS}_{2}$ nanoparticles on friction reduction in various lubrication regimes," Tribology Letters, vol. 17, no. 2, pp. 179-186, 2004.

[2] L. Joly-Pottuz, F. Dassenoy, M. Belin, B. Vacher, J. M. Martin, and N. Fleischer, "Ultralow-friction and wear properties of IF$\mathrm{WS}_{2}$ under boundary lubrication," Tribology Letters, vol. 18, no. 4, pp. 477-485, 2005.

[3] L. Yadgarov, V. Petrone, R. Rosentsveig, Y. Feldman, R. Tenne, and A. Senatore, "Tribological studies of rhenium doped fullerene-like $\mathrm{MoS}_{2}$ nanoparticles in boundary, mixed and elasto-hydrodynamic lubrication conditions," Wear, vol. 297, no. 1-2, pp. 1103-1110, 2013.
[4] R. Rosentsveig, A. Gorodnev, N. Feuerstein et al., "Fullerenelike $\mathrm{MoS}_{2}$ nanoparticles and their tribological behavior," Tribology Letters, vol. 36, no. 2, pp. 175-182, 2009.

[5] J. Wintterlin and M.-L. Bocquet, "Graphene on metal surfaces," Surface Science, vol. 603, no. 10-12, pp. 1841-1852, 2009.

[6] T. Ramanathan, A. A. Abdala, S. Stankovich et al., "Functionalized graphene sheets for polymer nanocomposites," Nature Nanotechnology, vol. 3, no. 6, pp. 327-331, 2008.

[7] P. J. Bryant, P. L. Gutshall, and L. H. Taylor, "A study of mechanisms of graphite friction and wear," Wear, vol. 7, no. 1, pp. 118-126, 1964.

[8] R. L. Fusaro, "Mechanisms of graphite fluoride $\left[\left(\mathrm{CF}_{x}\right)_{n}\right]$ lubrication," Wear, vol. 53, no. 2, pp. 303-323, 1979.

[9] T. Jun and X. Qunji, "The deintercalation effect of $\mathrm{FeCl}_{3}$ graphite intercalation compound in paraffin liquid lubrication," Tribology International, vol. 30, no. 8, pp. 571-574, 1997.

[10] M. R. Hilton, R. Bauer, S. V. Didziulis, M. T. Dugger, J. M. Keem, and J. Scholhamer, "Structural and tribological studies of $\mathrm{MoS}_{2}$ solid lubricant films having tailored metal-multilayer nanostructures," Surface and Coatings Technology, vol. 53, no. 1, pp. 13-23, 1992.

[11] J. Lin, L. Wang, and G. Chen, "Modification of graphene platelets and their tribological properties as a lubricant additive," Tribology Letters, vol. 41, no. 1, pp. 209-215, 2011.

[12] B. Bhushan and B. K. Gupta, Handbook of Tribology, McGrawHill, New York, NY, USA, 1991.

[13] W. Zhang, M. Zhou, H. Zhu et al., "Tribological properties of oleic acid-modified graphene as lubricant oil additives," Journal of Physics D, vol. 44, no. 20, Article ID 205303, 2011.

[14] H. D. Huang, J. P. Tu, L. P. Gan, and C. Z. Li, "An investigation on tribological properties of graphite nanosheets as oil additive," Wear, vol. 261, no. 2, pp. 140-144, 2006.

[15] W. S. Hummers Jr. and R. E. Offeman, "Preparation of graphitic oxide," Journal of the American Chemical Society, vol. 80, no. 6, p. 1339, 1958.

[16] “The history of Lonza's graphite powders," Industrial Lubrication and Tribolog, vol. 27, pp. 59-69, 1948.

[17] C. Altavilla, P. Ciambelli, M. Sarno et al., "Tribological and rheological behaviour of lubricating greases with nanosized inorganic based additives," in Proceedings of the 3rd European Conference on Tribology (ECOTRIB '11) and 4th Vienna International Conference on Nanotechnology (VIENNANO '11), F. Franek, W. J. Bartz, A. Pauschitz, J. Vizintin, E. Ciulli, and R. Crockett, Eds., pp. 903-908, Vienna.

[18] M. Kalin, I. Velkavrh, and J. Vižintin, “The Stribeck curve and lubrication design for non-fully wetted surfaces," Wear, vol. 267, no. 5-8, pp. 1232-1240, 2009.

[19] M. H. Cho, J. Ju, S. J. Kim, and H. Jang, “Tribological properties of solid lubricants (graphite, $\mathrm{Sb}_{2} \mathrm{~S}_{3}, \mathrm{MoS}_{2}$ ) for automotive brake friction materials," Wear, vol. 260, no. 7-8, pp. 855-860, 2006.

[20] L. M. Malard, M. A. Pimenta, G. Dresselhaus, and M. S. Dresselhaus, "Raman spectroscopy in graphene," Physics Reports, vol. 473 , no. 5-6, pp. 51-87, 2009.

[21] A. C. Ferrari, "Raman spectroscopy of graphene and graphite: disorder, electron-phonon coupling, doping and nonadiabatic effects," Solid State Communications, vol. 143, no. 1-2, pp. 47-57, 2007.

[22] M. A. Pimenta, G. Dresselhaus, M. S. Dresselhaus, L. G. Cançado, A. Jorio, and R. Saito, "Studying disorder in graphitebased systems by Raman spectroscopy," Physical Chemistry Chemical Physics, vol. 9, no. 11, pp. 1276-1291, 2007. 
[23] K. N. Kudin, B. Ozbas, H. C. Schniepp, R. K. Prud'homme, I. A. Aksay, and R. Car, "Raman spectra of graphite oxide and functionalized graphene sheets," Nano Letters, vol. 8, no. 1, pp. 36-41, 2008.

[24] L. Joly-Pottuz, E. W. Bucholz, N. Matsumoto et al., "Friction properties of carbon nano-onions from experiment and computer simulations," Tribology Letters, vol. 37, no. 1, pp. 75-81, 2010.

[25] O. Tevet, O. Goldbart, S. Cohen et al., "Nanocompression of individual multilayered polyhedral nanoparticles," Nanotechnology, vol. 21, no. 36, Article ID 365705, 2010.

[26] O. Tevet, P. Von-Huth, R. Popovitz-Biro, R. Rosentsveig, H. D. Wagner, and R. Tenne, "Friction mechanism of individual multilayered nanoparticles," Proceedings of the National Academy of Sciences, vol. 108, no. 50, pp. 19901-19906, 2011.

[27] G. Seifert, H. Terrones, M. Terrones, G. Jungnickel, and T. Frauenheim, "Structure and electronic properties of $\mathrm{MoS}_{2}$ nanotubes," Physical Review Letters, vol. 85, no. 1, pp. 146-149, 2000.

[28] B. V. Derjaguin and V. P. Smilga, "Electrostatic component of the rolling friction force moment," Wear, vol. 7, no. 3, pp. 270281,1964

[29] G. Liu, X. Li, B. Qin, D. Xing, Y. Guo, and R. Fan, "Investigation of the mending effect and mechanism of copper nano-particles on a tribologically stressed surface," Tribology Letters, vol. 17, no. 4, pp. 961-966, 2004.

[30] F. Dassenoy, L. Joly-Pottuz, J. M. Martin, and T. Mieno, "Carbon nanotubes as advanced lubricant additives," in Carbon Nanotubes, V. N. Popov and P. Lambin, Eds., vol. 222 of NATO Science Series II: Mathematics, Physics and Chemistry, pp. 237238, 2006. 

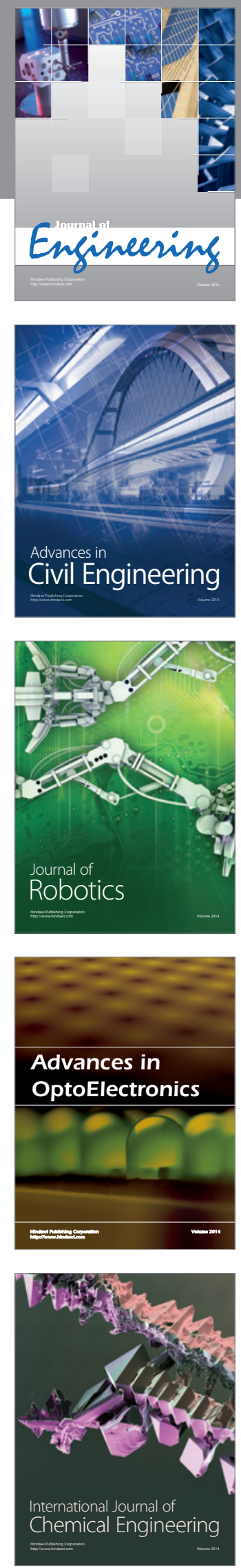

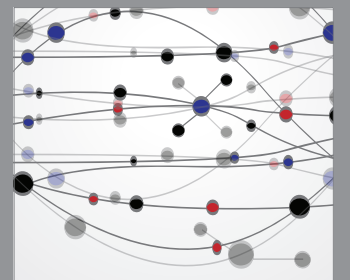

The Scientific World Journal
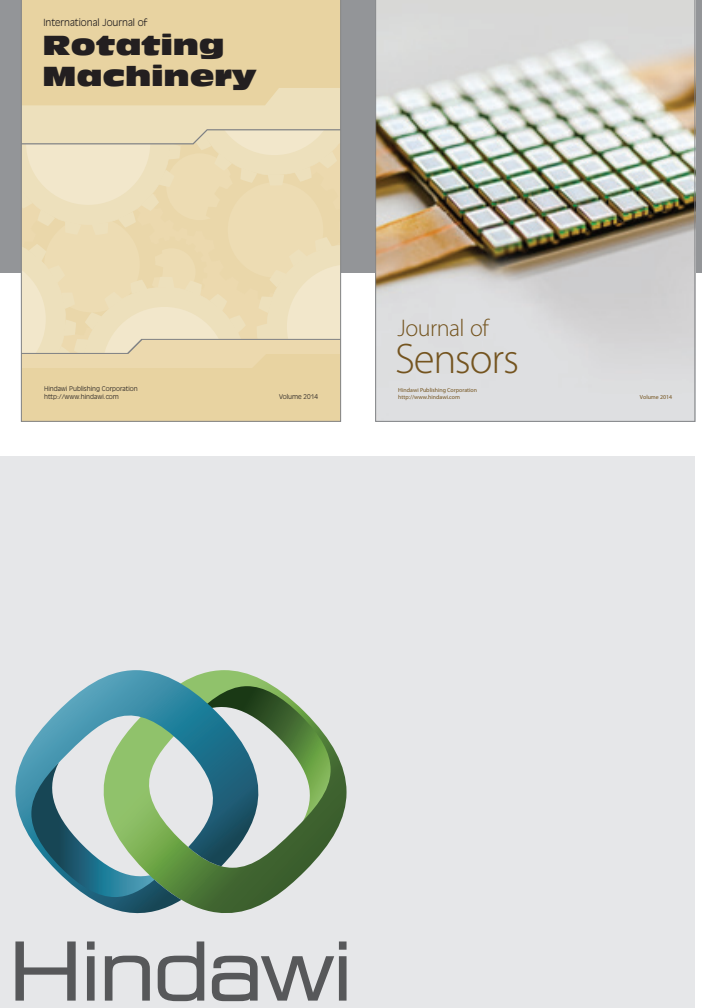

Submit your manuscripts at http://www.hindawi.com
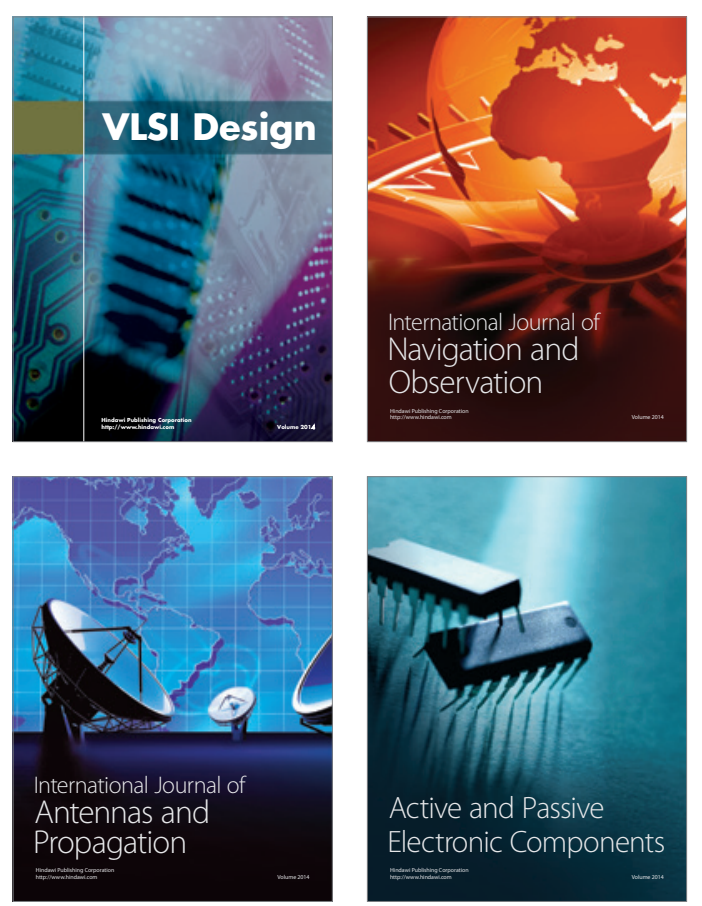
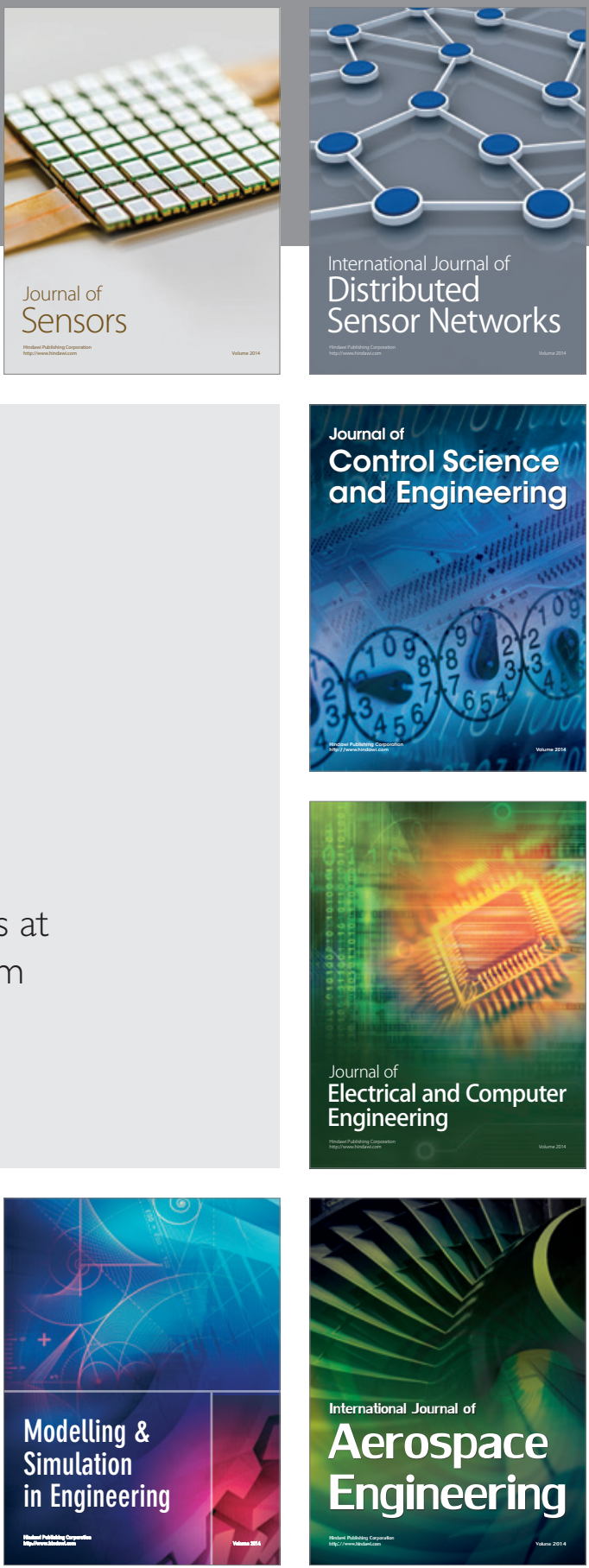

Journal of

Control Science

and Engineering
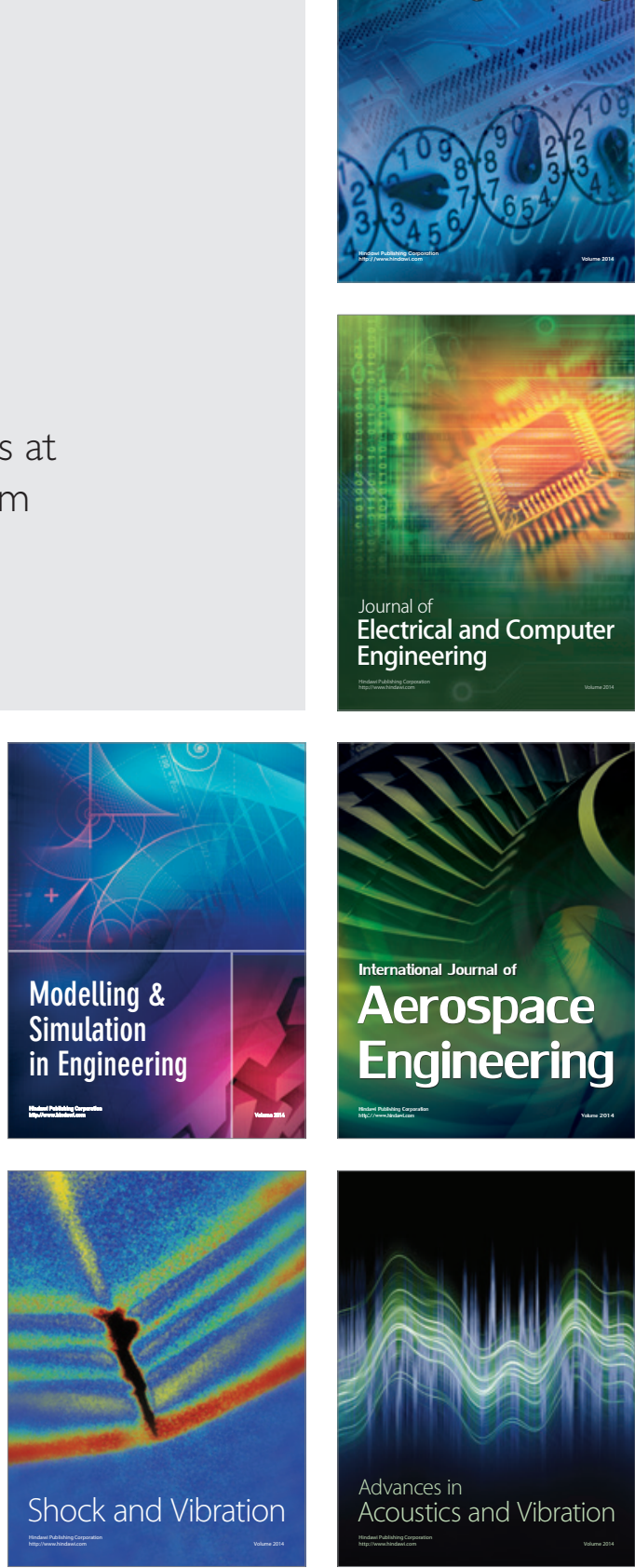